\title{
Numerical modelling of low-temperature non-equilibrium plasma of pulsing corona and breakdown
}

\author{
V.I.Chyhin; S.Y.Karpyak \\ Lviv Polytechnic National University, 12 Bandera Str., 79013 Lviv, Ukraine
}

Received July 6, 2006, in final form February 5, 2007

\begin{abstract}
The method of determining an existence region of the non-equilibrium plasma of the pulsating negative corona and breakdown is developed. The low-temperature non-equilibrium pulsing plasma of the point-to-plane negative corona and a transition form to the breakdown in nitrogen-oxygen mixture are numerically simulated. It is shown that plasma parameters are pulsing in time as well as in space. In the phase of corona pulse peak, its position adjoins the cathode surface, no further than $0.01 \mathrm{~cm}$. In the initial phase of breakdown, it extends far beyond the surface, within the distance of $0.03 \mathrm{~cm}$. At the same time, the electron temperature changes in almost full anti-phase to the current: from $9100 \mathrm{~K}$ to $19000 \mathrm{~K}$ during the corona pulse peak and from $6000 \mathrm{~K}$ to $20000 \mathrm{~K}$ in initial phases of the breakdown. The average plasma density changes in the range $7 \times 10^{11}-8 \times 10^{12} \mathrm{~cm}^{-3}$ in the first case and $1 \times 10^{13}-5 \times 10^{13} \mathrm{~cm}^{-3}$ in the case of breakdown.
\end{abstract}

Key words: corona discharge, breakdown, non-equilibrium plasma, numerical modelling

PACS: 52.80

\section{Introduction}

Gas discharge can become the neutral plasma as soon as two conditions are realized simultaneously: concentrations of electrons and positive ions are equal; the degree of ionization is high enough and it becomes impossible to separate charges due to their thermo-motions. In early monographs [1-3], the conditions of existence of the plasma in glow and arc discharges were defined. The plasma of pulsating negative corona discharge is mentioned in some works [4,5], but its quantitative description was not given. It is interesting to compare parameters of this plasma with the stationary negative corona plasma modelled in cylindrical geometry [6].

Results of investigations of the corona plasma find their application in making sensors of electronegative admixture concentration and gas pressure [7-11], in plasma-chemical reactors [12-14] etc. The pulsating negative corona and breakdown are caused by the application of high direct voltage to the point-plane electrode system. In some voltage region, the current pulses have high stable parameters. The main characteristics of low-frequency pulses and high-frequency current pulsation in nitrogen and argon with oxygen admixture were investigated [15-17]. This work develops the method of determining the existence region of low temperature non-equilibrium plasma of the discharges. Its basic parameters (co-ordinates, sizes, Debye length, energy of electrons and ions) are obtained in modelling the current pulse and breakdown development in nitrogen with oxygen admixture of $0.6 \%$ and $0 \%$ concentration, accordingly.

\section{Debye length in gas-discharge plasma}

It is easy to check the first condition of existence of the plasma in the calculation of concentration of charges. To verify the second condition it is necessary to calculate the spatial parameter of Debye length, and to compare it with the characteristic size of the gas discharge, such as the current tube

*E-mail: vchygin@polynet.lviv.ua 
diameter, etc. In some works [1-3], the question of determining the Debye length in gas-discharge plasma is partly disclosed. Following the conclusions in [1], where the energy of the coulomb interaction of charges is small compared to the thermal energy, one can get the solution of Poisson equation for the Debye length $\lambda_{\mathrm{D}}$ in the first approximation:

$$
\frac{1}{\lambda_{\mathrm{D}}^{2}}=\frac{4 \pi \mathrm{e}^{2} n_{\infty}}{k}\left(\frac{1}{T_{\mathrm{p}}}+\frac{1}{T_{\mathrm{e}}}\right)
$$

Here $T_{\mathrm{p}}$ and $T_{\mathrm{e}}$ is the ion and electron temperature, $n_{\infty}$ is the positive ion and electron concentration far from the center of the particle examined $\left(n_{\infty}=n_{\mathrm{e} \infty}=n_{\mathrm{p} \infty}\right)$, where the polarization disappears and the plasma becomes electro-neutral. In the non-equilibrium plasma, where the temperatures of electrons and ions are not equal (for example, in the weak-ionized gas-discharge plasma $T_{\mathrm{e}} \gg T_{\mathrm{p}}$ ), formally, according to the formula (1), the screening is determined by the low temperature of gas (of the order of $T_{\mathrm{p}}$ ) and the Debye length is very short. In the work [2], in the case of strongly nonisothermal plasma, the screening Debye length is defined by concentration and temperature of positive ions as well:

$$
\lambda_{\mathrm{D}}=\sqrt{\frac{k T_{\mathrm{p}}}{4 \pi \mathrm{e}^{2} n_{\mathrm{p}}}}
$$

This coincides with the formula [3]. As the author of [1] underlines, there is no complete clarity in the question of the effect of ions on the screening.

\section{Method of calculation of charge concentrations and field strength}

In the kinetic model of the negative corona we have taken into account the following processes: the ionization of $\mathrm{N}_{2}$ molecule due to collision with electron, the attachment of electron to $\mathrm{O}_{2}$, its detachment from $\mathrm{O}_{2}^{-}$due to collision with $\mathrm{N}_{2}$ in the ground-state, the drift of charges and the ion-electronic surface emission. Differential equations of the continuity for positive and negative ions and electron flows, supplemented with the Poisson equation for electric field in quasi twodimensional space, are put in the basis of numerical calculations [15]:

$$
\begin{aligned}
\frac{\partial n_{\mathrm{e}}}{\partial t}+\operatorname{div}\left(v_{\mathrm{e}} n_{\mathrm{e}}\right) & =\alpha n_{\mathrm{e}} v_{\mathrm{e}}-\eta n_{\mathrm{e}} v_{\mathrm{e}}+k_{d} n_{\mathrm{n}} n_{0} \\
\frac{\partial n_{\mathrm{p}}}{\partial t}-\operatorname{div}\left(v_{\mathrm{p}} n_{\mathrm{p}}\right) & =\alpha n_{\mathrm{e}} v_{\mathrm{e}} \\
\frac{\partial n_{\mathrm{n}}}{\partial t}+\operatorname{div}\left(v_{\mathrm{n}} n_{\mathrm{n}}\right) & =\eta n_{\mathrm{e}} v_{\mathrm{e}}-k_{d} n_{\mathrm{n}} n_{0} \\
\operatorname{div} E & =4 \pi e\left(n_{\mathrm{p}}-n_{\mathrm{e}}-n_{\mathrm{n}}\right)
\end{aligned}
$$

$n_{\mathrm{e}}, n_{\mathrm{p}}, n_{\mathrm{n}}$ are concentrations of electrons, positive and negative ions, $n_{0}$ - concentrations of main gas, $v_{\mathrm{e}}, v_{\mathrm{p}}, v_{\mathrm{n}}$ - their drift velocity, accordingly $\left(v_{\mathrm{e}}=b_{\mathrm{e}} E, b_{\mathrm{e}}\right.$ is the mobility assumed to be constant), $\alpha, \eta$, and $k_{d}$ - coefficients of an ionization, an attachment and a detachment. The current is defined as a sum of the displacement current and the current of p-ions at the cathode. A form of the current channel is set by two regions of a discharge space: the cathode one (cylindrical) and the drift one (parabolic).

The boundary conditions for positive and negative ions are self-evident; their number density is equal to zero at the anode and cathode, respectively. The boundary conditions for electrons at the cathode $(x=0)$ are formulated in terms of the secondary ion and photon emission coefficients, $\gamma_{i}$ and $\gamma_{\mathrm{ph}}$, accordingly:

$$
j_{\mathrm{e}}(0, t)=\gamma_{i} * j_{\mathrm{p}}(0, t),
$$

where $j_{\mathrm{e}}=n_{\mathrm{e}} v_{\mathrm{e}}$ and $j_{\mathrm{p}}=n_{\mathrm{p}} v_{\mathrm{p}}$ and

$$
n_{\mathrm{e}}^{\mathrm{ph}}(0, t)=\frac{1}{v_{\mathrm{e}}(0, t)} \cdot \frac{\gamma_{\mathrm{ph}}}{\tau} \int_{0}^{t} \mathrm{e}^{-\frac{t-t}{\tau}} \cdot \int_{0}^{d} n_{\mathrm{e}}(x, \hat{t})\left|v_{\mathrm{e}}(x, \hat{t})\right| \cdot \alpha^{*}(x, \hat{t}) \cdot \Omega(x) \cdot \mathrm{e}^{-\mu x} \mathrm{~d} x \mathrm{~d} t,
$$


where $\mu$ is the coefficient of the photon absorption, $\tau$ is the lifetime of the exited state, $\alpha^{*}$ is the excitation coefficient, $\Omega(x)$ is the solid angle extended at the cathode by the charge at $x[15], d$ is the space length.

Due to a very low current density of the negative corona and of an initial phase of the breakdown it was assumed that the room temperature of the gas is kept in all discharge points. Under this condition, the coefficients of kinetic processes, including the neutral particles, are constant in time, and those related to ionized particles are dependent only on the local field intensity. Consequently, it was assumed that the basic kinetic gas-discharge processes develop according to the following schemes:

- the molecule and atom $\left(M=\mathrm{N}_{2}, A r\right)$ ionization by an electron impact

$$
\mathrm{e}+M \rightarrow M^{+}+2 \mathrm{e}
$$

- the attachment of electron due to a collision of three particles ( $M$ is the third one, $\mathrm{N}_{2}$ or $A r$ )

$$
\mathrm{e}+\mathrm{O}_{2}+M \rightarrow \mathrm{O}_{2}^{-}+M
$$

- the electron detachment from $\mathrm{O}_{2}$ - ion by a molecule impact $\left(M=\mathrm{N}_{2}, A r\right)$

$$
\mathrm{O}_{2}^{-}+M \rightarrow \mathrm{O}_{2}+M+\mathrm{e}
$$

numerical data for kinetic coefficients (the main of them entered the table 1) are determined in the following way.

The process of atom and molecule ionization (9) by an electron impact in a wide energy region is well described in the monograph [1] (table 5.1, Townsend equation (5.25) and the extrapolation of experimental data, figures 5.4-5.6).

The three-body electron attachment (10) in the nitrogen-oxygen mixture uses coefficients given in [1]: $k_{a \mathrm{O}_{2}}$ - in the presence of only oxygen molecules and $k_{a N_{2}}$ - in the presence of nitrogen molecules. The field effect on the attachment rate has been simulated by the formula presented in [4] for pure oxygen. Here the value $k_{a \mathrm{O}_{2}}$ is divided by the function $k_{a}=k_{a \mathrm{O}_{2}}\left[1+(E / g / n)^{1.5}\right]^{-1}$,

\begin{tabular}{|c|c|c|c|c|c|c|}
\hline \multirow[t]{2}{*}{$\mathrm{N}$} & \multicolumn{3}{|c|}{ Coefficient } & \multicolumn{2}{|c|}{ Constant } & \multirow{2}{*}{ Energy range } \\
\hline & $\begin{array}{l}\text { Process } \\
\text { particle }\end{array}$ & $\begin{array}{c}\text { Symbol } \\
\text { dimension }\end{array}$ & Formula & & & \\
\hline 1 & $\begin{array}{l}\text { Ionization } \\
\mathrm{N}_{2}\end{array}$ & $\begin{array}{c}\alpha / p \\
(\mathrm{~cm} \cdot \text { tor })^{-1}\end{array}$ & $A \cdot \mathrm{e}^{-B p / E}$ & $\begin{array}{c}\mathrm{A} \\
8.8 \\
12.0\end{array}$ & $\begin{array}{c}\mathrm{B} \\
275 \\
342\end{array}$ & $\begin{array}{c}E / p, V /(\mathrm{cm} \cdot \text { tor }) \\
27-200 \\
200-600\end{array}$ \\
\hline 2 & $\begin{array}{l}\text { Attachment } \\
\mathrm{N}_{2}+\mathrm{O}_{2}\end{array}$ & $\begin{array}{c}k_{a} \\
\mathrm{~cm}^{6} / s\end{array}$ & $\begin{array}{c}k_{a \mathrm{~N}_{2}} n_{\mathrm{N}_{2}} n_{\mathrm{O}_{2}} \\
+\quad k_{a \mathrm{O}_{2}}\left(n_{\mathrm{O}_{2}}\right)^{2}\end{array}$ & $\begin{array}{l}0.16 . \\
+2.5 \text {. }\end{array}$ & $\begin{array}{l}k_{a \mathrm{~N}_{2}} \\
k_{a \mathrm{O}_{2}}\end{array}$ & $T=300 \mathrm{~K}$ \\
\hline 3 & $\begin{array}{l}\text { Detachment } \\
\mathrm{N}_{2}+\mathrm{O}_{2}^{-}\end{array}$ & $\begin{array}{c}k_{d} \\
\mathrm{~cm}^{3} / s\end{array}$ & $\begin{array}{c}f(E / n) \\
\text { graphic } \\
\& \text { tabular data }\end{array}$ & $\begin{array}{l}2 \cdot 1 \\
3.8\end{array}$ & & $\begin{array}{c}E / n=100 T d \\
E / n=1000 T d\end{array}$ \\
\hline
\end{tabular}
where $g$ is a constant for a given gaseous mixture.

Table 1. Formulas and coefficient constants of kinetic processes.

The electron detachment rate (11) at an impact of $\mathrm{O}_{2}^{-}$-ion with the unexcited nitrogen molecule under the room temperature is considered as follows [1]. It was taken into account that in the cathode region the field intensity increases to considerably high values of the order of $10^{5} \mathrm{~V} / \mathrm{cm}$. 

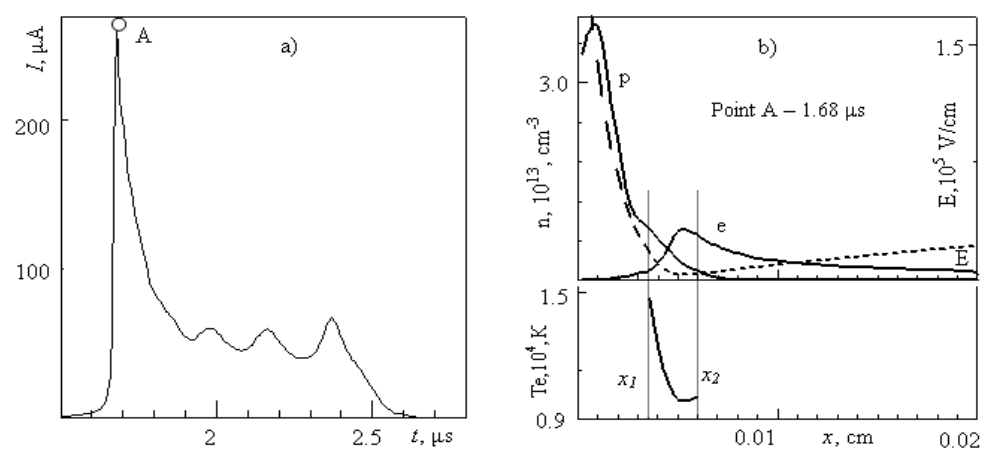

Figure 1. Temporal dependence of the corona current (a); (b) the concentration of electrons $e$ and ions $p$, the field strength $E$ and the electron temperature $T_{\mathrm{e}}$ in the plasma dependencies on the distance $x$ to the point at the time instant $\mathrm{A}$ in figure $1 \mathrm{a}$.

Under these conditions the drift velocity of electrons, positive nitrogen and argon ions and negative oxygen ions were taken from work [1].

Taking into account that the dissociative electron attachment e $+\mathrm{O}_{2} \rightarrow \mathrm{O}^{-}+\mathrm{O}$ has caused the change of air corona parameters no more than $5 \%$ [18] and that the oxygen content is too low in our case, this process was not taken into consideration. There was not considered the $\mathrm{O}_{2}$ ionization by electron impact and the direct two-body attachment e $+\mathrm{O}_{2} \rightarrow \mathrm{O}_{2}^{-}$as well. Since positive and negative ions are almost fully separated in space during the pulsation period of the negative corona, and the passing time of electrons through the positive ion cloud (placed in a very narrow cathode sheath) is short in comparison with the pulse duration, we excluded recombination electron-ion and ion-ion processes from consideration. Detailed information about the modelling is possible to find in the work [15].

\section{Method of calculation of plasma parameters}

Boundaries $x_{1}$ and $x_{2}$ of a possible existence of the plasma have been determined from conditions of a proximity of electron and positive ion concentrations obtained at a solution of equations (3)(6). Namely, there was used the equation $n_{\mathrm{e}}=0.2 \cdot n_{\mathrm{p}}$ to get $x_{1}$ and $n_{\mathrm{p}}=0.2 \cdot n_{\mathrm{e}}$ to get $x_{2}$. Figure 1 and figure 2 present the schemes of determining the co-ordinates $x_{1}$ and $x_{2}$ in cases of the corona and the breakdown in nitrogen with the oxygen admixture. Common parameters of discharges: the applied voltage to the discharge gap $-2300 \mathrm{~V}$, the point radius $-0.004 \mathrm{~cm}$, the gap length $-0.6 \mathrm{~cm}$, the generation region length $-0.02 \mathrm{~cm}$. Differing parameters: the external resistance $-10^{6} \mathrm{Ohm}$ and $10^{4} \mathrm{Ohm}$, the oxygen concentration $-0.6 \%$ and $0 \%$ in figure 1 and figure 2 , accordingly.

We have used the formula (2) to calculate the Debye length of the non-equilibrium plasma of negative corona. The following method was adopted to calculate the electron and positive ion temperatures in gas discharges. With the calculated field strength $E(9)$ we find the velocity of positive ion as $v_{\mathrm{p}}=b_{\mathrm{p}} E$, where $b_{\mathrm{p}}$ is its mobility, which is a constant value $[1,2]$. Then, the ion temperature $T_{\mathrm{p}}$ is set by the relation [5]:

$$
T_{\mathrm{p}}=293+6 \cdot 10^{-9} A_{\mathrm{p}} v_{\mathrm{p}}^{2},
$$

where $A_{\mathrm{p}}$ is the atomic mass unit for ions $\left(28-\right.$ for $\left.\mathrm{N}_{2}\right)$.

The electron temperature was found, having preliminary determined the characteristic energy of $D_{i} / b_{i}, \mathrm{eV}$, using the method described in the work [2] ( $D_{i}$ is the ion drift coefficient). Setting the electric field, we determine the reduced strength $E / p, V / \mathrm{cm} /$ tor, where $p$ is the gas pressure. Using this $E / p$ and the experimental graph for nitrogen in figure 11.3.5 [2], one can calculate $D_{i} / b_{i}$ 

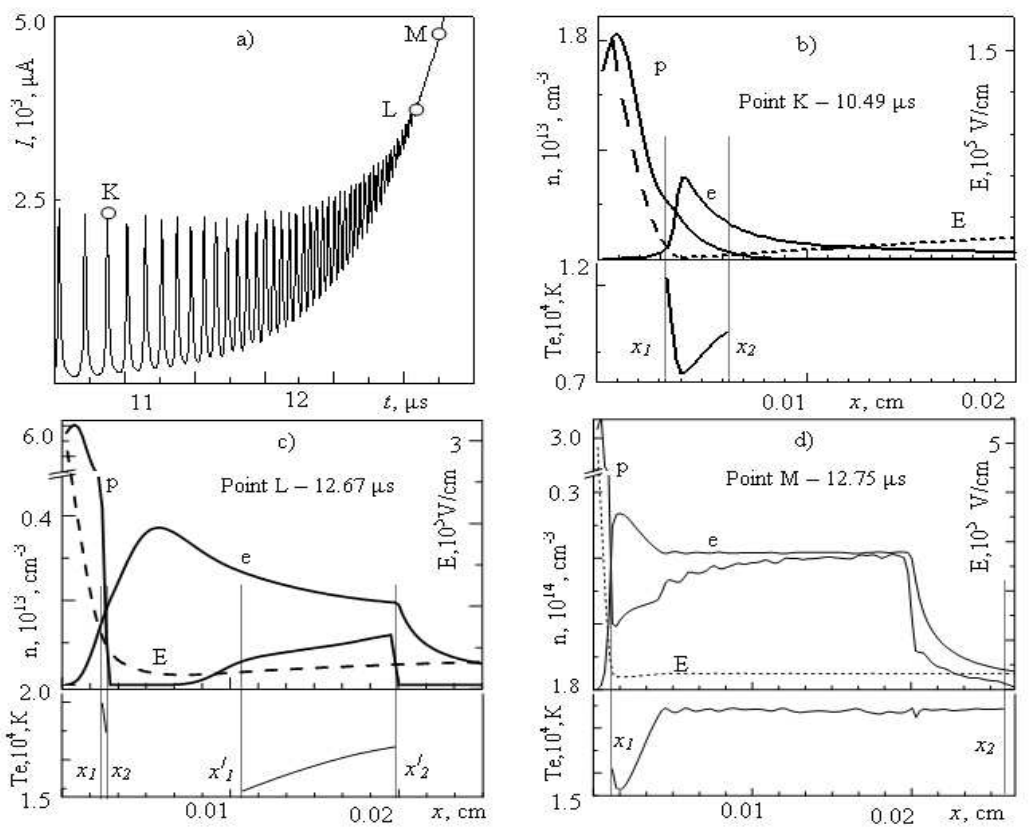

Figure 2. (a) Temporal dependence of breakdown current. (b), (c), (d) Dependencies of concentration of electrons $e$ and ions $p$, field strength $E$ and electron temperature $T_{\mathrm{e}}$ on distance $x$ to the point at moments K, L, M (figure $2 \mathrm{a}$ ).

due to the interpolation formula:

$$
D_{i} / b_{i}=1.16876 x /(0.74044+x)+0.02108 x,
$$

where $x=E / p$. Dividing the received value by means of the thermal energy of gas molecules at $20 C^{\circ}\left(k T_{20}=0.026 \cdot 20 / 15=0.0347 \mathrm{eV}, k T_{15}=0.026 \mathrm{eV}\right.$, figure 11.3.5 [2] $)$, we determine the Townsend power coefficient (dimensionless):

$$
\eta=D_{i} / 0.0347 b_{i} .
$$

The mean-square speed of electron is calculated with the formula 11.3.3 [2]:

$$
v_{\mathrm{e}}=1.15 \cdot 10^{7} \eta^{0,5}, \mathrm{~cm} / \mathrm{s} .
$$

Then we get the average electron energy in the plasma:

$$
\varepsilon=m_{\mathrm{e}} v_{\mathrm{e}}^{2} / 2, \mathrm{erg},
$$

or $\varepsilon_{1}=\varepsilon / 1.6 \cdot 10^{-12}, \mathrm{eV}\left(m_{\mathrm{e}}-\right.$ is the electron mass $)$. Finally, the electron temperature is found by [2]:

$$
T_{\mathrm{e}}=2 / 3 \cdot 11610 \varepsilon_{1}, \mathrm{~K}^{\circ} .
$$

\section{Results and analysis}

\subsection{Plasma parameters of pulsing corona}

It is obvious from figure 3 that the distance of $\Delta x=x_{2}-x_{1}$ in the cathode generation region, in which the concentration of electrons and positive ions is close enough, is very narrow (of the order of 


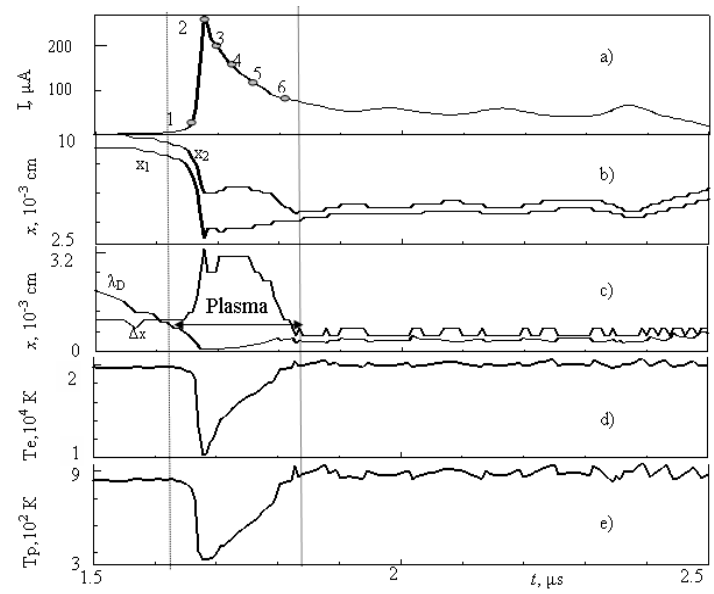

Figure 3. The calculated temporal dependencies. (a) Pulse current (in moments 1-6 electron temperature is calculated, figure 4). (b) Distances $x_{1}$ and $x_{2}$ to the point, where $n_{\mathrm{e}}=0.2 \cdot n_{\mathrm{p}}$ and $n_{\mathrm{p}}=0.2 \cdot n_{\mathrm{e}}$. (c) Interval $\Delta x=x_{2}-x_{1}$ and Debye length $\lambda_{\mathrm{D}}$. d) Electron temperature $T_{\mathrm{e}}$. (d) Positive ion temperature $T_{\mathrm{p}}$. Discharge parameters are the same as in figure 1.

$0.0007-0.0010 \mathrm{~cm})$ during full time of the pulse passing, except for its peak part $(1.65-1.83 \mu \mathrm{s})$. In the latter case, $\Delta x$ increases sharply to the maximal value of $0.0032 \mathrm{~cm}$ at the moment of the maximum current of the pulse (the point 2 in figure $3 \mathrm{a}, t=1.678 \mu \mathrm{s}$ ), and then it quickly decreases to $0.0007 \mathrm{~cm}$. The effect of the high-frequency current pulsation on the value of $\Delta x$ is not noticeable. It is interesting to note that before the beginning of the current corona growth, co-ordinates $x_{1}$ and $x_{2}$ are close to the middle of the set generation region length $(0.01 \mathrm{~cm})$. At the moments of maximal increase of the current, the co-ordinate $x_{1}$ falls sharply to the value of $0.0025 \mathrm{~cm}$, then it increases fluently to $0.0045 \mathrm{~cm}$, whereas the $x_{2}$ goes down considerably weaker, and only at the moments of the post-peek current decrease it increases weakly to the value of $0.065 \mathrm{~cm}$. Such a behavior of co-ordinates $x_{1}$ and $x_{2}$ causes a substantial expansion of the region of $\Delta x$ mentioned above.

The range of variation of the calculated Debye length $\lambda_{\mathrm{D}}$ is high during the period of corona pulsation. Up to the moment of the current increase, its value is much higher, than at the moment of pulse peak, where it falls to nearly zero value of $5.9 \cdot 10^{-5} \mathrm{~cm}$. Later, the $\lambda_{\mathrm{D}}$ fluently increases to the value of $6 \cdot 10^{-4} \mathrm{~cm}$. Out-of-pulse, the Debye length increases rapidly again to the values of the order of centimeters, considerably exceeding $\Delta x$. This dynamics of $\lambda_{\mathrm{D}}$ is directly connected with the charge concentration that is strongly dependent on the phase of current pulse development. The middle concentration of $n_{\mathrm{e}}$ and $n_{\mathrm{p}}$ is of the order of $2.0 \cdot 10^{8} \mathrm{~cm}^{-3}$ at $t=0.4 \mu \mathrm{s}$ and $3.0 \cdot 10^{9} \mathrm{~cm}^{-3}$ at $t=1.3 \mu \mathrm{s}$ (the pulse origin). It rapidly increases to $1.0 \cdot 10^{13} \mathrm{~cm}^{-3}$ at $t=1.684 \mu \mathrm{s}$ (the current peak, point $\mathrm{A}$ in the figure 1) and fluently decreases to $0.7 \cdot 10^{12} \mathrm{~cm}^{-3}$ at the moment of about $1.78 \mu \mathrm{s}$ (a completion of the pulse peak). Then, the concentration falls down sharply to the value of $2.0 \cdot 10^{9} \mathrm{~cm}^{-3}$ at $t=4.5 \mu \mathrm{s}$ (the end of the pulse). Further, in the off period it continues to decrease. Thus, the second condition of the corona discharge plasma existence $\left(\lambda_{\mathrm{D}} \ll \Delta x\right)$ is fulfilled only in the short time interval of the pulse peak part - from 1.67 to $1.78 \mu \mathrm{s}$, that amounts to nearly $1 / 60$ of the pulse duration.

As it is obvious from figure $3 \mathrm{~d}$, the temporal dependence of the electron temperature is in almost full antiphase to the proper dependence of corona current. At the relatively constant value $T_{\mathrm{e}}\left(1.9 \cdot 10^{4} \mathrm{~K}\right)$ until the pulse beginning, it decreases sharply at the current amplitude moment $(t=1.678 \mu \mathrm{s})$ and then it fluently increases to the values higher than initial. This value is constant outside the pulse. In figure $3 \mathrm{e}$, the similar picture of plasma ion temperature is possible to observe. The difference from $T_{\mathrm{e}}(t)$ consists in a more considerable increase of the $T_{\mathrm{p}}$ value in the after-peak period. 


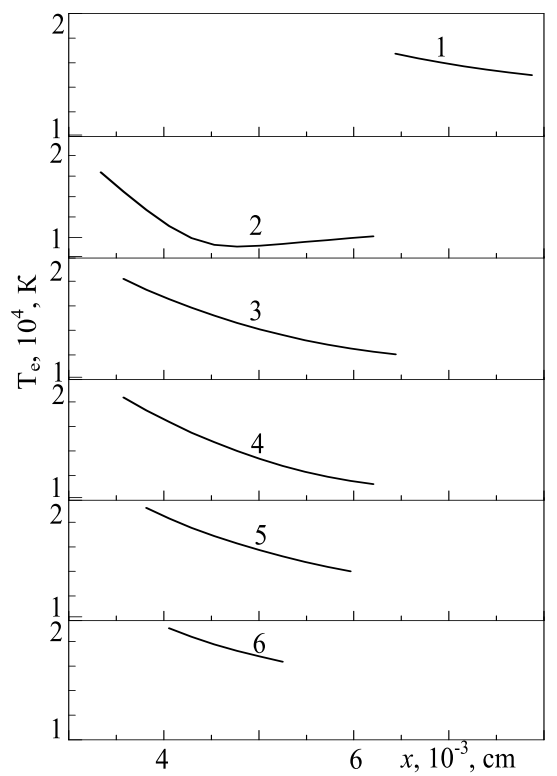

Figure 4. Dependencies of electron temperature $T_{\mathrm{e}}$ on the distance to the point. The same data as in figure 3 .
In figure 4, the graphs of electron temperature dependence on the distance of point clearly demonstrate the dynamics of plasma region and its position in the evolution process of corona current pulse at the moments 1-6 (figure 3a). Apparently, at the initial moments of the current increase, the plasma is at a far distance from the point and its width is small, of the order of $1.4 \cdot 10^{-3} \mathrm{~cm}$ (moment 1). As the current increases to maximal value, the plasma sharply approaches the cathode surface and at the moment 2 its width $\Delta x$ increases to $0.003 \mathrm{~cm}$ at the moment 2. After the current peak, the plasma width decreases again, almost 3 times (moments 3-6), and its midposition floats insignificantly within limits of $4.5 \cdot 10^{-3}-5.0 \cdot 10^{-3} \mathrm{~cm}$. The turn-down of electron temperature in plasma also substantially depends on the phase of current pulse development. At first, as the corona current is low (moment 1 ), the $T_{\mathrm{e}}$ range is very narrow $\left(1.5 \cdot 10^{4}-1.7 \cdot 10^{4} K\right)$. In the pulse peak, the range of temperatures acquires the maximal value $\left(0.9 \cdot 10^{4}-1.6 \cdot 10^{4} K\right)$, but the middle temperature goes substantially down. After the current maximum passes, the electron temperature increases again up to maximal value $1.9 \cdot 10^{4} \mathrm{~K}$ and the plasma range narrows (moment 6 ). At all time moments, except the point 2, this temperature goes fluently down with the increase of the distance to the cathode. At the peak moment, the dependence $T_{\mathrm{e}}(x)$ is essentially nonlinear, with the minimum at $x=4.6 \cdot 10^{-3} \mathrm{~cm}$. At the current peak moment the dependence $T_{\mathrm{e}}(x)$ is essentially nonlinear, with a minimum at $x=4.6 \cdot 10^{-3} \mathrm{~cm}$.

\subsection{Plasma parameters of gas breakdown}

It is evident from figure 2 that the breakdown plasma pulsates constantly both in the space of generation region (figure $2 \mathrm{~b}, \mathrm{c}$ ) during the current pulsation (near the points $\mathrm{K}-\mathrm{L}$, figure 2a) and at the time of in-phase with the current. The plasma region is extended far from the surface to the drift region (figure 2d) in phases of the non-pulsating breakdown (between points L-M, figure 2a). It is interesting to note that the transition to the last breakdown plasma is possible through the existence of two plasma volumes in the cathode generation region (figure 2c). In initial phases of the breakdown, the electron temperature changes in almost full anti-phase to the current, from $6000 \mathrm{~K}$ to $20000 \mathrm{~K}$. The average breakdown plasma density has values of the order of $1 \cdot 10^{13}-5 \cdot 10^{13} \mathrm{~cm}^{-3}$.

\subsection{Comparison with stationary corona plasma}

The described pulsations of basic parameters of the non-equilibrium plasma of the negative corona and breakdown are obtained for the first time. So far, only in one work [6] the modelling of the negative corona plasma in the cylindrical geometry in dry air was carried out. Here, all plasma parameters were constant in time. Two conditions of the plasma existence were not checked. Two plasma boundaries were accepted arbitrarily. The first one was placed on the cathode surface; the second one was calculated as the boundary of generation region, using the condition of equality of coefficients of the reproduction and attachment of electrons. Between these boundaries, the electric field corresponds to the middle kinetic energy of electrons of $1.85 \mathrm{eV}$; in other words, this is the region in which the electron impact reactions run. Out of this region, the electron attachment 
to oxygen molecules and the formation of negative $\mathrm{O}_{2}^{-}$ions only exist. In our opinion, such an approach is doubtful in relation to the strictness of implementation of the classical plasma physics requirements.

\section{Conclusions}

1. The method of determining the existence region of non-equilibrium plasma of pulsating negative corona and breakdown is developed, using the equations of charges flows and Poisson equation for electric field; the plasma characteristics are calculated.

2. It is shown that the plasma pulsates constantly both in the space of generation region during the corona pulse peak and far from the surface in the initial phase of breakdown, and at the time of in-phase with the current

3. The obtained electron temperature and concentration confirm the relation of the plasma of pulsing negative corona and initial phase of breakdown to the class of low temperature non-equilibrium plasma.

4. The theory of corona and breakdown discharge plasma needs further development, in particular, in determining the Debye length.

\section{References}

1. Raizer Yu.P. Physics of Gas Discharge, Moscow, Nauka, 1987 (in Russian).

2. McDaniel E. Collision Processes in Ionised Gases. Mir, Moscow, 1967 (in Russian).

3. Granovsky V.L. Electrical Current in Gas. Gostechizdat, Moscow, 1971 (in Russian).

4. Morrow R. Phys. Rev. A., 1985, 32, No. 3, 1799.

5. Akishev Yu., et al. Plasma Physics, 2001, 27, No. 5, 1 (in Russian).

6. Chen J., Davidson J. Plasma Chemistry and Plasma Processing, 2003, 23, 83.

7. Polyakova A., et al. Mass-spectral analysis of mixtures with use of ion-molecular reactions. Chimia, Moscow, 1989 (in Russian).

8. Chyhin V. Ukraine patent No. 25169, 1998.

9. Chyhin V., Prots O. Theory and designing of semiconductor and radio-electronic devices. Bull. of NU "Lvivska Polytekhnika", 1999, No. 343, 180 (in Ukrainian).

10. Sigmond R.S. - In Proc. 11th Int. Symp. Plasma Chemistry, Loughborough, 1993, p. 1.

11. Chyhin V. Research Eng. Report, No. 7033, NU "Lvivska Polytekhnika", 2003, 24 p.

12. Spyrou N., Peyrous R., Held B. J. Phys. D: Appl. Phys., 1994, 27, 2329.

13. Dors M., Mizeraczyk J. J. Electrostatics, 1998, 45, 25.

14. Chyhin V. Int. Symp. HAKONE, Greifswald, 2000, p. 103.

15. Chyhin V. Condens. Matter Phys., 2002, 5, 429.

16. Chyhin V. Probl. Atomic Science and Technol. Plasma Physics, 2005, No. 1, 178.

17. Chyhin V. Probl. Atomic Science and Technol. Plasma Physics, 2005, No .2, 185.

18. Napartovich A., et al. J. Phys. D: Appl.Phys., 1997, 30, 2726. 


\title{
Чисельне моделювання низькотемпературної нерівноважної плазми пульсуючої корони та пробиття
}

\author{
В.І.Чигинь, С.Ю.Карп'як \\ Національний Університет “Львівська Політехніка”, Львів 79013, вул. С. Бандери 12 \\ Отримано 6 липня 2006 р., в остаточному вигляді - 5 лютого 2007 р.
}

Запропоновано метод визначення області існування нерівноважної плазми корони і газового пробиття. Низькотемпературна нерівноважна пульсуюча плазма негативної корони між вістрям і площиною та перехідної форми до пробиття чисельно змодельована у суміші азоту і кисню. Показано, що параметри плазми пульсують, як у часі, так і в просторі розряду. Вона розміщується безпосередньо біля поверхні катода, не далі, ніж 0.01 см у фазі піку імпульсу корони і високочастотного імпульсу пробиття, і розширюється у межах 0.03 см від поверхні до дрейфової області у початковій фазі пробиття. Температура електронів змінюється у майже повній антифазі до струму: від 9100 до 19000 K протягом піку імпульсу корони і від 6000 до 20000 К у початкових фазах пробиття. Усереднена густина плазми приймає значення $7 \cdot 10^{11}-8 \cdot 10^{12} \mathrm{~cm}^{-3}$ у першому випадку і $1 \cdot 10^{13}-5 \cdot 10^{13} \mathrm{~cm}^{-3}$ у випадку пробиття.

Ключові слова: коронний розряд, пробиття, нерівноважна плазма, чисельне моделювання

PACS: 52.80 
